\title{
Pursuing the evolution of the Asian Tethyan realm - Third International Symposium of IGCP-589
}

\section{1-22 October 2014, Tehran, Iran}

The Third International Symposium of IGCP-589 "Development of the Asian Tethyan Realm: Genesis, Process and Outcomes" was held between $21^{\text {st }}$ and $22^{\text {nd }}$ October, 2014 in the Amirkabir Technical University, Tehran, Iran. The symposium was preceded by a two-day pre-symposium fieldexcursion (October 19-20) and followed by a four-day post-symposium field excursion (October 23-26). With the total involvement of the Geological Survey of Iran, the organizer of this event, the hospitality of Amirkabir Technical University, and the active support of IUGS and UNESCO, this event has been successfully conducted.

More than 30 delegates from China, Germany, India, Iran, Italy, Japan, Malaysia, Poland, Thailand, and Turkey participated in this event and exchanged their latest findings and achievements on evolution of the Tethys. Twenty one oral presentations and 10 poster presentations with good participation among women and students dealt with the key problems of Asian Tethyan realm. Papers covered different disciplines of geological sciences in resolving the Tethyan issues and highlighted the importance of multidisciplinary approaches of the projects presented. Deliberations on various problems of common concern, such as stratigraphical correlation, paleogeogrphic evolution, petrological assemblages, tectonic configuration, identification of similarities and differences between the different parts of the Tethyan Realm and a common minimum programme to address the irresolvable issues were the highlights of the symposium.

Choosing Iran as the place to convene this event owes to not only its significant geographic location with excellent geological records of the development of the western Tethys, but also the good geological research capacity of the country and the involvement of international teams.

Pre-symposium and post-symposium excursions were designed to provide the participants an opportunity to (i) visit the places, where the closing of the Paleo-Tethys and subsequent evolution are well demonstrated, and (ii) see the places, that

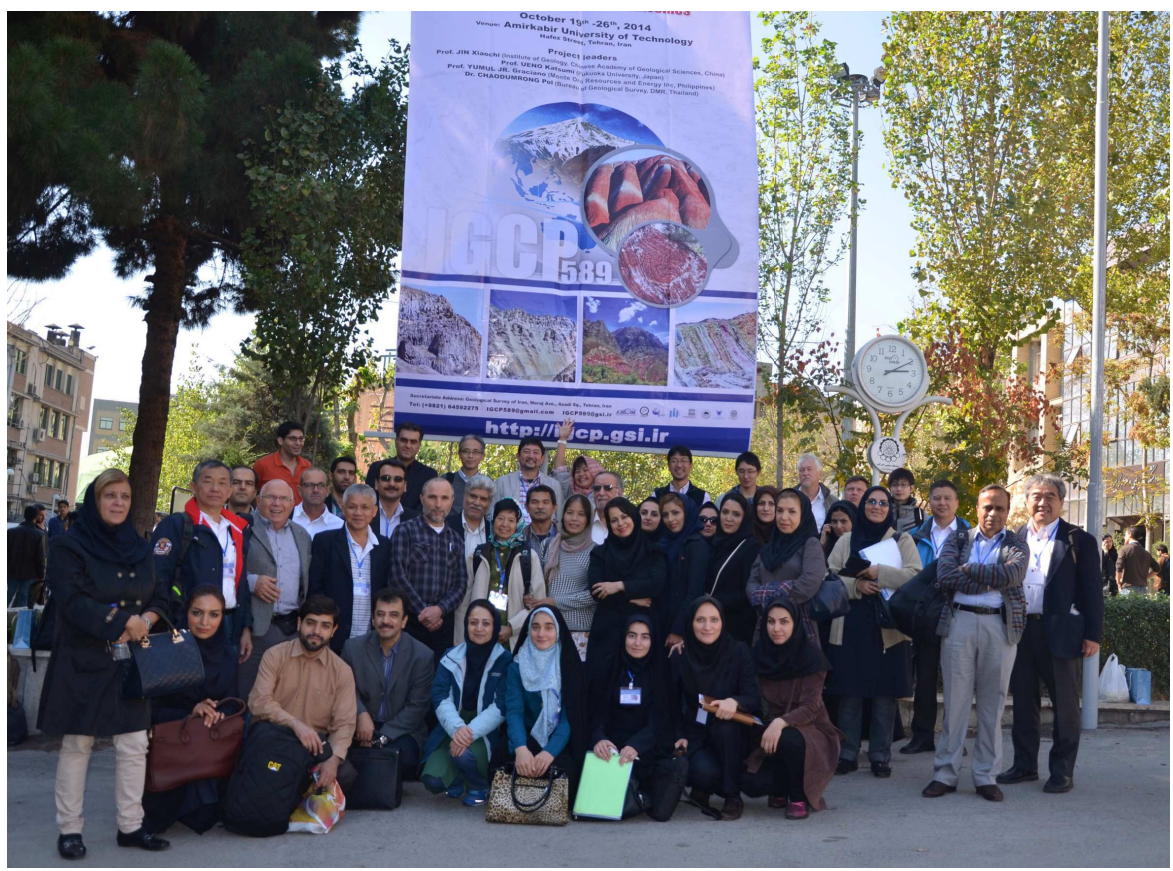

Symposium participants gather under a large poster of the symposium in front of the venue.

recorded the drift of the Cimmerian blocks and evolution of the Neotethys. As a result the Alborz Mountains became the target area of the Pre-symposium excursion, and the central Iran blocks and the Sanandaj-Sirjan zone became the objective of the postsymposium excursion. In addition to studying the critical geological sections, participants also enjoyed during the pre-symposium excursion the nice green landscapes and loft mountains in the Alborz, and during the postsymposium excursion wild landscape in central Iran and lively historical cities of Yazd and Isfahan.

The IGCP project 589 is led by Xiaochi Jin (China), Katsumi Ueno (Japan), Graciano Yumul Jr. (Philippines), and Pol Chaodumrong (Thailand). The project started in 2012 and held its inaugural international symposium in Xi' an, China and second in 2013 in Boracay Island, Philippines. Field excursions were successfully conducted in the Qinling Orogen in central China and Panay Island of Philippines respectively. It was decided, amongst other matters, at the business meeting on the second day of the symposium that the fourth international symposium of IGCP-589 will be held next year in Thailand. Field excursions are planned to be conducted in northern Thailand, a geologically very complicated region that accommodates the complexes of eastern Paleo-Tethyan suture(s). Prof. Jin Xiaochi thanked the Iranian colleagues for excellent hospitality and for the successful organization of the symposium and field excursions. $\mathrm{He}$ also invited the delegates to participate in yet another exhilarating experience next year at Thailand.

\section{Xiaochi Jin,}

Institute of Geology,

Chinese Academy of Geological Sciences, 26 Baiwanzhuang Road,

Beijing 100037, China;

E: jinxchi@cags.ac.cn; jinxchi@sina.com,

\section{Mohammad Ghassemi}

Research Institute for Earth Sciences, Geological Survey of Iran, Meraj Ave., Azadi Sq., Tehran, Iran 